\author{
() Т.С. Паневин ${ }^{1,2,3}$, Л.И. Алексеева' ${ }^{1}$ Е.А. Таскина' ${ }^{1}$ Н.Г. Кашеварова ${ }^{1}$
}

'ФГБНУ «Научно-исследовательский институт ревматологии им. В.А. Насоновой», Москва, Россия ${ }^{2}$ ФГБУ «Национальный медицинский исследовательский центр эндокринологии», Москва, Россия ${ }^{3}$ ФГКУ «Консультативно-диагностический центр Генерального штаба Вооруженных сил Российской Федерации»

В отсутствие адекватного лечения сахарный диабет (СД) может привести к развитию поздних осложнений. Помимо «классических» осложнений, отмечена высокая распространенность поражения опорно-двигательного аппарата при СД. Наиболее целесообразным термином, отражающим данное состояние, является «синдром ограниченной подвижности суставов» (ОПС). Поражение кистей при ОПС характеризуется безболезненной ригидностью суставов, фиксированными сгибательными контрактурами, нарушением мелкой моторики и силы захвата. Со временем ОПС развивается не только в мелких суставах кистей, но и в других суставах конечностей. Традиционно синдрому ОПС уделяется меньшее внимание со стороны практикующих специалистов в сравнении с другими микро- и макрососудистыми осложнениями СД, даже несмотря на то, что ОПС может значимо нарушать функциональную активность, самообслуживание и ухудшать качество жизни. Предполагается, что повреждения околосуставных тканей и суставов при СД вызваны накоплением конечных продуктов гликирования. Решающее место в диагностике ОПС занимает клинический осмотр. Поскольку при синдроме ОПС могут поражаться костно-суставные структуры стоп, своевременная диагностика данного осложнения может способствовать выявлению пациентов с повышенным риском развития синдрома диабетической стопы.

КЛЮЧЕВЫЕ СЛОВА: сахарный диабет; конечные продукты гликирования; синдром ограниченной подвижности суставов; диабетическая стопа; полинейропатия

\title{
LIMITED JOINT MOBILITY SYNDROME AS A PREDICTOR OF THE DIABETIC FOOT SYNDROME
}

(c) Taras S. Panevin ${ }^{1,2,3}$, Lyudmila I. Alekseeva', Elena A. Taskina' ${ }^{1}$ Natalia G. Kashevarova'

'V.A. Nasonova Research Institute of Rheumatology, Moscow, Russia

${ }^{2}$ Endocrinology Research Centre, Moscow, Russia

${ }^{3}$ Advisory and Diagnostic center of the General Staff of the Armed Forces of the Russian Federation

Diabetes mellitus (DM) can lead to the development of late complications. In addition to the traditional late complications, a high prevalence of damage to the musculoskeletal system in diabetes was noted. The most appropriate term that reflects the defeat of the musculoskeletal system in diabetes is «limited joints mobility syndrome» (LJM). Damage to the hands in the presence of open painless stiffness of the joints, fixed flexion contractures, impaired fine motor skills of the hands and grip forces. Subsequently, it became clear that, over time, the restriction of joint mobility develops not only in the small joints of the hands, but also in other large and small joints of the limbs. Traditionally, LJM syndrome pays low attention on the part of practitioners in comparison with other micro- and macrovascular complications of diabetes, even though LJM can significantly impair functional activity, self-care, and impair the quality of life. It is assumed that damage to the periarticular tissues and joints in DM is caused by the accumulation of end glycation products. A decisive place in the diagnosis of LJM is the clinical examination. In the presence of LJM syndrome, the osteoarticular structures of the feet can be affected, timely diagnosis can lead to the development of diabetic foot syndrome.

KEYWORDS: diabetes mellitus; advanced glycation end products; limited joint mobility syndrome; diabetic foot; polyneuropathy

\section{ВВЕДЕНИЕ}

Сахарный диабет (СД) представляет собой группу обменных заболеваний, характеризующихся хронической гипергликемией вследствие нарушения секреции инсулина, его действия либо сочетания этих двух факторов. В отсутствие адекватного лечения СД может приводить к развитию поздних осложнений, к которым относят микроангиопатии (ретинопатия, нефропатия) и макроангиопатии (атеросклероз брахиоцефальных, коронарных артерий, ар- терий нижних конечностей, которые могут привести к инфаркту миокарда, острому нарушению мозгового кровообращения и синдрому диабетической стопы) [1].

Помимо «классических» поздних осложнений, отмечена высокая распространенность поражения опорно-двигательного аппарата (ОДА) при СД [2]. Первые работы в данной области датированы 50-ми годами XX в., когда было отмечено, что у лиц с длительным течением СД1 развивается ограничение подвижности суставов кистей. Первое описание таких пациентов принадлежит 
K. Lundbaek в 1957 г. [3]. В 1974 г. A. Rosenbloom и колл. [4] отметили связь между тугоподвижностью мелких суставов кистей и длительностью течения СД1 у детей. Так появился термин «диабетическая хайроартропатия» - поражение соединительнотканных структур кисти в условиях персистирующей гипергликемии, приводящее к ограничению подвижности суставов, как правило, в отсутствие болевого синдрома. В последующих работах была отмечена взаимосвязь между ограничением подвижности суставов кистей и микрососудистыми осложнениями СД [5]. Так, наличие ограничения подвижности суставов при СД1 было ассоциировано с четырехкратным повышением риска микрососудистых осложнений в сравнении с группой СД1 без ограничения подвижности [6]. Далее было отмечено, что со временем ограничение подвижности суставов развивается не только в мелких суставах кистей, но и в других крупных и мелких суставах конечностей. Таким образом, более целесообразным понятием, отражающим поражение ОДА при СД, стало «синдром ограниченной подвижности суставов» (ОПС).

Кроме того, при СД чаще, чем в общей популяции, встречаются поражения ОДА, не попадающие под классическое определение синдрома ОПС, такие как синдром «замороженного» плеча, разрыв вращательной манжеты плечевого сустава, контрактура Дюпюитрена, синдром «щелкающего пальца», а также синдром карпального канала (рис. 1) [7]. Распространенность ОПС варьирует от 8 до 58\%, в зависимости от исследуемых групп пациентов с СД и спектра скелетно-мышечных нарушений, включаемых в данное понятие [8-10]. В популяции без нарушений углеводного обмена отдельные проявления ОПС встречаются в 4-26\% случаев [11].

Поражение кистей при ОПС характеризуется безболезненной ригидностью суставов, фиксированными сгибательными контрактурами, нарушением мелкой моторики и силы захвата, в пожилом возрасте возможны незначительная боль и парестезии, характерна «восковидная кожа». В случае наличия последнего симптома может потребоваться дифференциальная диагностика с системной склеродермией при помощи капилляроскопии ногтевого ложа и иммунологического анализа (антинуклеарный фактор, антисклеродермические антитела) [12]. Классическими подтверждающими клиническими методами диагностики хайроартропатии, использованными в большинстве предыдущих исследований, являются «тест молящегося» (Prayer sign) и «тест опоры на столешницу» (Table top sign), но их можно применить только при отсутствии ранее перенесенных выраженных травматических повреждений и оперативных вмешательств, которые могли бы повлиять на возможность полного разгибания исследуемой кисти [13]. Высокоспецифичные лабораторные и инструментальные исследования, подтверждающие синдром ОПС, на сегодняшний день отсутствуют.

Традиционно синдрому ОПС уделяется меньшее внимание со стороны практикующих специалистов в сравнении с другими микро- и макрососудистыми осложнениями СД, даже несмотря на то, что ОПС ассоциировано с поздними осложнениями и может значимо нарушать функциональную активность, самообслуживание, ухудшать качество жизни пациента [14].

Патогенез ОПС многокомпонентен (рис. 2) и включает регулярную механическую микротравматизацию структур ОДА, субклиническое воспаление, генетическую предрасположенность, а также иммунологические и биохимические изменения. Кроме того, макрососудистые осложнения, сенсорная полинейропатия, миопатия, снижение почечной функции, ассоциированные с СД, могут влиять на мышечную силу, функцию суставов, ограничивая диапазон движений.

Предполагается, что повреждения околосуставных тканей и суставов при СД вызваны накоплением конечных продуктов гликирования (КПГ, АGE) [15], которое происходит с возрастом и существенно ускоряется в условиях персистирующей гипергликемии. Избыток КПГ может приводить к образованию поперечных связей внутри молекулы коллагена, что вызывает нарушение функциональных свойств связываемого белка [16]. Наибольшее накопление КПГ происходит в тканях с медленным обновлением белковых молекул, таких как хрящевая, костная, и в ткани сухожилий. КПГ взаимодействуют с различными AGE-связывающими рецепторами на по-
- Адгезивный капсулит

\section{Плечевой сустав}

- Повреждения вращательной манжеты

- Комплексный регионарный болевой синдром

- Кальцифицирующий тендинит

\begin{tabular}{|l|}
\multicolumn{1}{c|}{ Кисть } \\
- Хайроартропатия \\
- Контрактура Дюпюитрена \\
- Сгибательный теносиновит \\
- Карпальный туннельный синдром
\end{tabular}

\section{Основные ревматические проявления сахарного диабета}

\begin{tabular}{|l|}
\multicolumn{1}{c|}{ Нижняя конечность } \\
• Нейроостеоартропатия Шарко \\
• Остеолиз костей переднего отдела стопы \\
• Липоидный некробиоз \\
\hline
\end{tabular}

\begin{tabular}{|l|}
\hline \multicolumn{1}{c|}{ Прочие } \\
- Диффузный идиопатический гиперостоз \\
(болезнь Форестье) \\
- Остеопороз \\
- Болезнь депонирования пирофосфата кальция \\
- Синдром Рейно \\
\hline
\end{tabular}

Рис. 1. Ревматические заболевания, ассоциированные с сахарным диабетом 


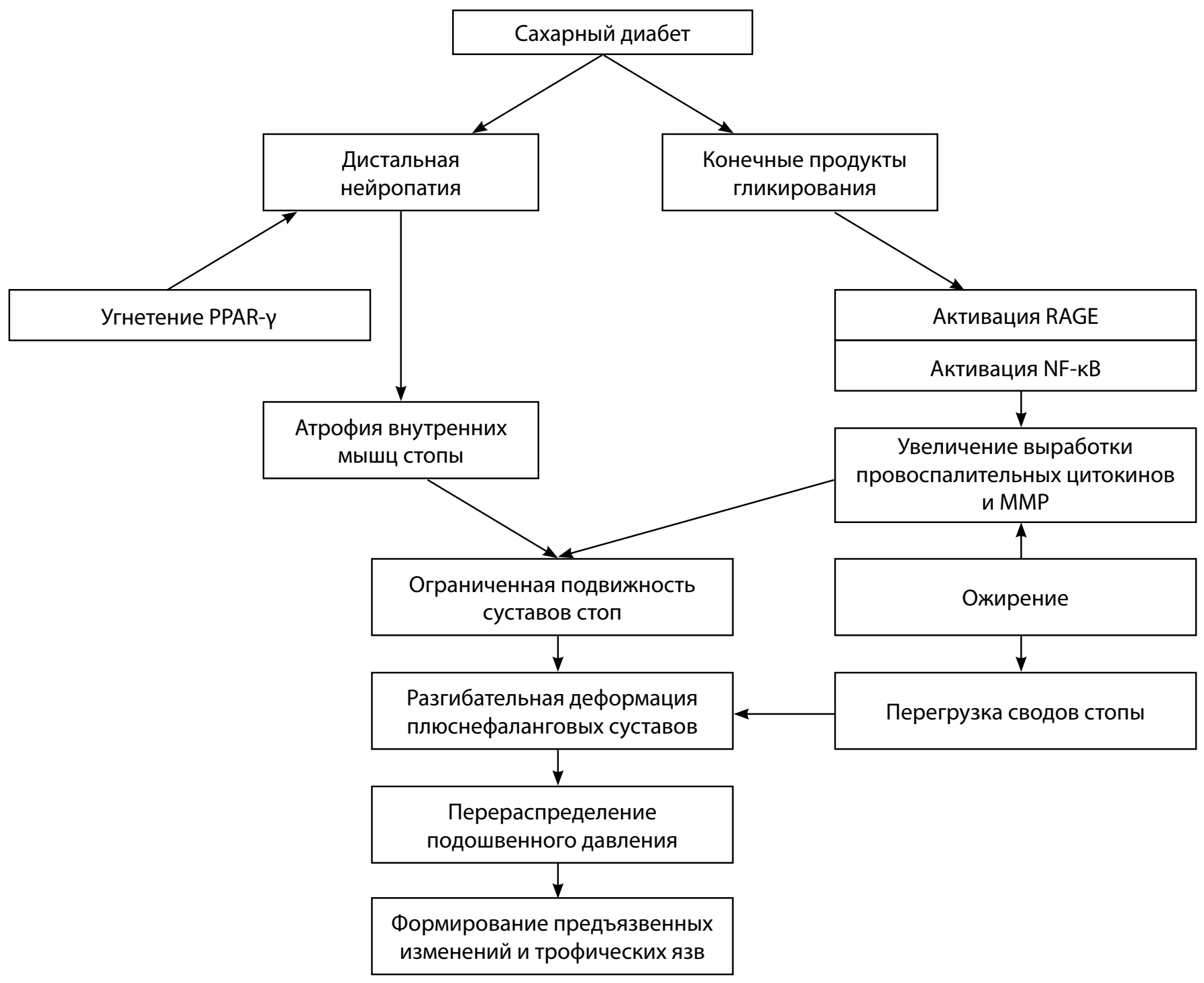

Рис. 2. Влияние ОПС на развитие язвенных дефектов стоп.

MMP - матриксные металлопротеиназы; PPAR - гамма-рецепторы, активируемые пролифераторами пероксисом; RAGE - рецепторы к конечным продуктам гликирования; NF-кB - ядерный фактор кB.

верхности клеток (AGE-R1, AGE-R2, AGE-R3 и RAGE) [17], что приводит к увеличению провоспалительной активности через сигнальный путь ядерного фактора (nuclear factor) кB (NF-кB), а также увеличивает внутриклеточное перекисное окисление липидов, продуцируя избыток активных форм кислорода.

Другие негативные эффекты КПГ включают модификацию короткоживущих белков, таких как фактор роста фибробластов, что приводит к снижению митогенной активности; внутриклеточное образование КПГ, приводящее к разрушению оксида азота и нарушению передачи сигналов фактора роста; повышенную активность каспаз и внеклеточную передачу сигналов через проапоптотические цитокины [18]. Кроме того, показано, что повышенные концентрации матриксных металлопротеиназ 2 и 9, а также их ингибиторов были обнаружены у лиц с недостаточным контролем СД и с большим стажем заболевания [19]. Избыток КПГ приводит к снижению уровня гамма-рецепторов, активируемых пролифератором пероксисом (PPAR-ү), что может ограничивать нейрогенез и ангиогенез, уменьшая созревание нейрональных клеток-предшественников, разрастание аксонов, выживание нейронов и пролиферацию шванновских клеток [20]. Это приводит к нарушению восприятия болевого импульса и повреждению соединительнотканных структур.

Сообщается о более частой кальцификации сухожилий, в частности, ахиллова сухожилия у пациентов с СД, что может быть следствием некротических процессов в ткани сухожилий, а также разрыва коллагеновых волокон и гиалиновой дегенерации [21]. Многие морфогенетические белки (остеопонтин, декорин, аггрекан, бигликан и фибромодулин) могут быть вовлечены в эктопический хондрогенез и последующее окостенение [22]. Отмечено снижение васкуляризации сухожилий по данным ультразвуковой доплерографии, а также уменьшение содержания фактора роста эндотелия сосудов, снижение ангиогенеза [23]. Кроме того, кальцификация сухожилий может быть обусловлена вторичным гиперпаратиреозом в рамках диабетической нефропатии [24].

Наконец, СД2 часто связан с избыточной массой тела, висцеральным ожирением, при которых имеет место повышенная нагрузка на ОДА, а также избыточная продукция адипокинов, что приводит к поддержанию системного воспаления и нарушению гомеостаза тканей ОДА [25]. 


\section{СИНДРОМ ОГРАНИЧЕННОЙ ПОДВИЖНОСТИ СУСТАВОВ НИЖНЕЙ КОНЕЧНОСТИ}

Синдром диабетической стопы (СДС) является актуальной проблемой: ежегодная заболеваемость в развитых странах составляет 1-4\%. Около 85\% всех ампутаций предшествует диабетическая трофическая язва стопы, а каждые 20 секунд в мире происходит одна ампутация из-за СДС [26]. Ограничение подвижности суставов приводит к развитию сложных деформаций, что является одним из основных факторов риска развития язвенных дефектов стоп [27]. Объем движений суставов стоп уменьшается не только при наличии СД, но и с возрастом, поэтому ОПС у пожилых людей с длительным анамнезом СД является следствием как гипергликемии, так и старения [15]. Само по себе ОПС не вызывает появление язвенных дефектов стоп, но способствует их возникновению при наличии сенсорной полинейропатии. Так, у больных ревматоидным артритом, имеющих аномально высокое давление на отдельные участки подошвы, но не имеющих полинейропатии, не развивалось изъязвление стоп [28]. Таким образом, комбинация тяжелой сенсорной нейропатии и ОПС определяет такого пациента в группу высокого риска СДС. В одном из исследований [29] продемонстрирована связь между ОПС и высоким подошвенным давлением, а также выраженная корреляция между величиной пикового давления и наличием СДС в анамнезе. Результаты данного исследования также показали, что ни у одного пациента с ОПС в отсутствие периферической нейропатии не развился СДС.

Впервые в 1956 г. W. Oakley и колл., помимо взаимосвязи между периферической нейропатией и язвами стоп, отметили, что наличие ригидных и деформированных пальцев стоп вместе с отсутствием нормальных движений стопы во время ходьбы приводит к нарушению ее нормальной анатомической конфигурации. Данные изменения могут приводить к появлению гиперкератоза и образованию безболезненных язвенных дефектов [30]. В 1985 году L. Delbridge и колл. предположили, что у таких пациентов может происходить перераспределение нагрузки с пальцев на плюсневые головки, вероятно, из-за пареза мышц стопы [31]. В последующем отмечено, что ограничение разгибания большого пальца стопы (hallux limitus) в сочетании с сенсорной полинейропатией может вызывать образование язвенных дефектов на кончике и под первым пальцем у пациентов с СД, и что данное состояние можно заметить, наблюдая за походкой пациента при клиническом осмотре [32].

Голеностопный, подтаранный и плюснефаланговые суставы (ПлФС) играют ключевую роль в нормальной амортизации и распределении нагрузки в стопе как при вертикальной статической нагрузке, таки при ходьбе. Функционирование подтаранного сустава имеет решающее значение для биомеханики: движение в нем происходит во всех плоскостях. Во время ходьбы нижняя конечность должна отвечать двум требованиям: изначальная подвижность и последующая жесткость. От точки контакта пятки до нагрузки передней части стопы необходима ее подвижность за счет пронации подтаранного сустава, что обеспечивает адаптацию к поверхности и инициирует амортизацию удара с последующей немедленной супинацией, что позволяет создать рычаг для последующего отталкивания.
Одно из самых значимых исследований по данному вопросу было проведено L. Delbridge и соавт. [33] в 1988 г. Показано, что ограниченная подвижность суставов является системным явлением у пациентов с СД и не ограничивается верхней конечностью, а снижение подвижности в суставах стопы способствует формированию язвенных дефектов. В данной работе была изучена подвижность суставов кисти, подтаранного сустава и первого пальца стопы с помощью гониометра у 42 пациентов с СД при наличии или отсутствии нейропатической язвы в анамнезе и у 20 здоровых контрольных субъектов. Согласно результатам, средний диапазон движения (в градусах) в подтаранном суставе для каждой из трех групп составил соответственно: контроль $35,2 \pm 2,3$; СД $31,1 \pm 1,7$; группа СД с наличием язвенных дефектов стоп $17,9 \pm 2,9$. Диапазон движений для пациентов с СД и нейропатическими язвами значительно отличался как от группы контроля ( $p=0,0001)$, так и от пациентов с СД без язв $(p=0,004)$. Разница между этими двумя последними группами не достигла статистической значимости $(p=0,16)$.

Существовала статистически значимая связь между диапазоном движений в подтаранном и I ПлФС Данная связь оставалась достоверной также только для пациентов с СД ( $r=0,63, p<0,01)$. Кроме того, существовала статистически значимая связь между подвижностью $V$ пальца кисти и диапазоном движения в подтаранном суставе $(r=0,41, p<0,01)$, которая оставалась достоверной $(r=0,32, p<0,05)$ когда рассматривались только пациенты с СД. Аналогичная взаимосвязь существовала между подвижностью $V$ пальца кисти и амплитудой движения в I плюснефаланговом суставе как для всей группы $(r=0,57, p<0,01)$, так и только для пациентов с диабетом $(r=0,49, p<0,01)$. Отмечено, что объем движений в подтаранном суставе чаще уменьшен в той стопе, где развился язвенный дефект $(p=0,029)$. Кроме того, с увеличением степени выраженности изменений кисти происходит постепенное снижение объема движений в подтаранном суставе $(f=3,71, p<0,05)$.

Ограниченная подвижность голеностопного сустава сочетается со снижением тонуса внутренних мышц стопы, что может вносить вклад в формирование разгибательной деформации ПлФС. Ограничение тыльного сгибания в голеностопном суставе у пациентов с СД может быть вызвано в том числе утолщением ахиллова сухожилия [34]. Cheuy V. и колл. показали, что уменьшение мышечного объема в передней части стопы и ОПС голеностопного сустава ассоциированы с разгибательной деформацией в ПлФС за счет увеличения давления на переднюю часть стопы при ходьбе. Увеличение КПГ, оцениваемое по косвенному показателю кожной иммунофлюоресценции, было связано с тяжестью полинейропатии [35]. По результатам исследований, общая подвижность голеностопного сустава менее $45^{\circ}$ указывает на наличие риска развития СДС, особенно у пациентов с полинейропатией [36].

Метаанализ A. Searli [37], включавший 15 исследований с 2544 участниками в возрасте от 45 до 80 лет и продолжительностью СД от 1 до 31 года, оценивал влияние ограничения подвижности голеностопного сустава на риск развития язвенных дефектов. В большинстве исследований определение ОПС проводилось с помощью 
гониометра. В пяти исследованиях также было определено подошвенное давление. Метаанализ показал, что наличие ограничения подвижности голеностопного сустава имело достоверный, но небольшой эффект увеличения подошвенного давления (размер эффекта Hedges $g=0,26$; ДИ 95\% от 0,11 до 0,$41 ; p=0,001$ ) без значимой гетерогенности (I2=0,0\%; $\mathrm{p}=0,92)$, что было связано с преимущественным влиянием результатов большого исследования Lavery и соавт. [38]. Из оставшихся 12 исследований в 8 сообщалось о наличии связи между ограничением подвижности голеностопного сустава и повышенным подошвенным давлением, в то время как четыре исследования не обнаружили такой взаимосвязи. Во всех включенных исследованиях, где целевая популяция выборки имела в анамнезе нейропатический язвенный дефект, была обнаружена связь между ограничением дорсифлексии голеностопного сустава и увеличением подошвенного давления. Такая связь не была обнаружена в тех исследованиях, где наблюдались нейропатия и отсутствие язвенных дефектов в анамнезе.

Деформация в ПлФС имеет место до 85\% у лиц с трофическими язвами и ампутацией в анамнезе [39]. Данная разновидность деформации передней части стопы обычно описывается как «молоточкообразная» или «когтеобразная». Она обусловлена ослаблением внутренних мышц стопы, которое предшествует ослаблению наружного разгибателя I пальца стопы в результате моторной нейропатии [40]. Считается, что данные изменения происходят из-за потери мышечной массы и инфильтрации межмышечной жировой ткани [41]. В результате нарушения баланса между внутренними мышцами стопы в присутствии относительно более сильных внешних разгибателей пальцев ног (m. extensor digitorum longus) развивается гиперэкстензия ПлФС. Повышенная зависимость от разгибателя большого пальца стопы в сочетании с недостаточной стабилизацией ПлФС внутренними мышцами стопы может привести к укорочению разгибателя большого пальца стопы и вызвать гиперэкстензию в ПлФС. Определение подвижности голеностопного сустава или I ПлФС является простым и довольно точным тестом и поэтому может быть полезно в качестве инструмента скрининга при СД для выявления пациентов с риском развития СДС. Показано, что подвижность в голеностопном суставе и I ПлФС была значительно снижена у пациентов с диабетической полинейропатией в сравнении с больными с СД без полинейропатии, а также с группой без диабета [42].

Подошвенный апоневроз вплетается спереди в проксимальную фалангу каждого из пяти пальцев и сзади в пяточную кость, поддерживая тем самым продольные своды стопы [43]. Он богат коллагеном и, поэтому, подвержен воздействию КПГ. Подошвенная плюсневая область и пальцы являются типичными зонами для развития нейропатических язв [44]. Melling М. и соавт. [45] обнаружили выраженное утолщение ладонного апоневроза у взрослых пациентов с диабетом по сравнению с контрольной группой без СД, однако эластические свойства существенно не различались. Ладонный и подошвенный апоневроз являются гомологичными структурами, поэтому, возможно, и стоит ожидать схожих изменений структуры при СД. С помощью УЗИ показано, что толщина подошвенного апоневроза больше у пациентов с СД1 и ассоциирована с размером стопы, высоким ИМТ, мужским полом и ОПС в подтаранном суставе. У мужчин вероятность утолщения подошвенного апоневроза почти в три раза выше, чем у женщин [46]. Вероятно, большая масса тела увеличивает механическую нагрузку на подошвенный апоневроз. Утолщение апоневроза может приводить к вертикализации пяточной кости, уменьшая объем движений в подтаранном суставе.

Таким образом, развитие деформации стоп является многофакторным процессом, включающим ОПС, утолщение подошвенного апоневроза и нарушение структурной однородности сухожилий. Указанные изменения могут развиваться с возрастом, однако персистирующая гипергликемия существенно ускоряет данные процессы. Нарушение правильной конфигурации стоп приводит к появлению зон избыточного давления, что при наличии дистальной сенсорной нейропатии тяжелой степени может приводить к развитию язвенных дефектов. В рамках объективного обследования необходимо проводить оценку подвижности I плюснефалангового и голеностопного суставов. Общая подвижность голеностопного сустава менее $45^{\circ}$ и пассивное тыльное сгибание 1 ПлФС менее $50^{\circ}$ ассоциированы со значительным увеличением риска развития язвенных дефектов при наличии полинейропатии. Исследование объема движений суставов может быть выполнено с помощью гониометра или инклинометра. К сожалению, на сегодняшний день отсутствуют стандарты оценки подвижности суставов у таких пациентов [47]. Для оценки распределения нагрузки на подошву во время ходьбы может быть использована педобарография.

\section{ЛЕЧЕНИЕ}

В основе профилактических мероприятий развития синдрома ОПС лежит адекватный контроль гликемии и достижение индивидуальных целевых показателей на всем протяжении с момента установки диагноза СД [48]. Специфические методы лечения диабетической нейропатии и синдрома ОПС с полноценной доказательной базой на сегодняшний день отсутствуют. При наличии болевого синдрома может быть использована анальгетическая терапия (парацетамол, антидепрессанты, прегабалин). Дозировки препаратов соответствуют указанным в рекомендациях по лечению диабетической нейропатии, необходимо титрование доз антидепрессантов и антиконвульсантов для улучшения переносимости и минимизации побочных эффектов [1]. Оперативное лечение проводится при выраженных функциональных ограничениях. В зависимости от выраженности и характера деформаций могут быть использованы остеотомия плюсневых костей, экономные резекции головок плюсневых костей и основных фаланг, коррекция длины сухожилий путем тенотомии и транспозиции.

В ряде исследований отмечено положительное влияние на кисти и стопы лечебной физкультуры [49]. Еще в 1934 г. Elliot Joslin предложил включить лечебную физкультуру в комплексную терапию пациентов с СД с язвенными дефектами стоп [50]. В начале 1980-х гг. P. Brand и J. Birke с коллегами разработали комплексный подход для лечения нейропатических язв, включающий физиотерапию и медикаментозную терапию, 
а также реабилитацию [51, 52]. В XXI в. был проведен ряд исследований по изучению влияния лечебной физкультуры на пациентов с ОПС с или без диабетической дистальной нейропатии и анамнезом изъязвлений [53]. Однако улучшения подвижности суставов, достигнутые с помощью лечебной физкультуры, могут быть потеряны, по крайней мере частично, через несколько месяцев после окончания периода лечения [54]. Хотя результаты исследований явно демонстрируют, что существенные краткосрочные улучшения объема движений могут быть достигнуты всего за несколько недель, фактическое влияние данных протоколов на походку пока не известно, требуется проведение дальнейших исследований. Необходим профессиональный уход за стопами, специализированная ортопедическая или сложная ортопедическая обувь, индивидуальная при стопе Шарко с выраженной деформацией или при трансметатарзальной резекции стопы [55]. При умеренном риске развития СДС возможно использование обуви по готовой колодке (как правило, повышенной глубины) с индивидуально изготовленной ортопедической стелькой. При высоком риске СДС необходимо использовать обувь по индивидуальной колодке с индивидуальной ортопедической стелькой. Подбор обуви должен осуществляться совместно с ортопедом. Коррекция ортопедических стелек осуществляется не реже 2 раз в год. При изготовлении обуви необходимо помнить, что обувь для пациентов с СД принципиально отличается от ортопедической обуви, применяемой при других заболеваниях. С целью снижения нагрузки на подошвенную поверхность используется специальная конструкция подошвы (ригидная подошва с «перекатом»), а также стельки из амортизирующих материалов толщиной не менее 5-10 мм. Индивидуальные ортопедические стельки учитывают особенности строения и функции опорно-двигательного аппарата. Ортопедическая обувь должна отвечать следующим требованиям: минимальное количество швов, ширина обуви не меньше, чем ширина стопы, дополнительный объем обуви для вложения ортопедической стельки, мягкий подносок, регулируемость объема с помощью шнурков или застежки.

Оценка эффективности ортопедической обуви и необходимости ортопедической коррекции проводится клинически, а также с помощью педобарографии. Данный метод имеет преимущество в сравнении с фотоплантографией и рентгенографией, поскольку может показать области избыточного подошвенного давления как в статическом, так и в динамическом состоянии на протяжении всего цикла шага. Компьютерная визуализация изменения давления на опорной поверхности стопы дает возможность подобрать оптимальное ортопедическое решение, снижающее до минимума патологическое воздействие на стопу [56].

Препараты, которые потенциально можно использовать для предотвращения накопления КПГ, в настоящее время находятся на стадии исследований и пока не имеют доказательной базы безопасного применения у человека $[57,58]$. Перспективные положительные результаты получены при применении рекомбинантного растворимого рецептора к КПГ на животных моделях [59].

\section{ЗАКЛЮЧЕНИЕ}

Таким образом, патологические изменения, приводящие к образованию язвенных дефектов стоп при СД, являются следствием периферической полинейропатии, а также изменения костно-суставных структур. Учитывая частоту ограниченной подвижности суставов, достигающую 50\%, и то, что ОПС сопровождается микрососудистыми и угрожающими конечностям осложнениями, скрининг ОПС у пациентов с диабетом важен и должен быть частью ежегодного или, при необходимости, более частого обследования. При развитии вышеупомянутых деформаций стоп в сочетании с нарушением чувствительности пациенты относятся к группе умеренного риска развития СДС и должны быть осмотрены не реже 1 раза в 6 месяцев. При развитии более тяжелых деформаций (H. valgus III-IV степени, а также деформаций вследствие нейроостеоартропатии) - 1 раз в 3 месяца [1]. Изменения ОДА нижних конечностей развиваются одновременно с диабетической хайроартропатией. Учитывая отсутствие высокоэффективных методов лечения ОПС, а также простоту и доступность осмотра кистей, как и стоп, целесообразно проводить его при каждом визите пациента к эндокринологу, поскольку раннее выявление позволяет сохранять большую функциональную активHOCTb.

\section{ДОПОЛНИТЕЛЬНАЯ ИНФОРМАЦИЯ}

Конфликт интересов. Авторы декларируют отсутствие явных и потенциальных конфликтов интересов, связанных с публикацией настоящей статьи.

\section{СПИСОК ЛИТЕРАТУРЫ | REFERENCES}

1. Дедов И.И., Шестакова М.В., Майоров А.Ю., и др. Алгоритмы специализированной медицинской помощи больным сахарным диабетом. / Под ред. Дедова И.И., Шестаковой М.В., Майорова А.Ю. 9-й выпуск. // Сахарный диабет. - 2019. — Т. 22. — №1S1. C. 1-144. [Dedov II, Shestakova MV, Mayorov AY, et al. Standards of specialized diabetes care. Ed. by Dedov II, Shestakova MV, Mayorov AY. 9th ed. Diabetes mellitus. 2019;22(1S1):1-121. (In Russ.)] doi: https://doi.org/10.14341/dm221s1

2. Rosenbloom AL, Silverstein JH. Connective Tissue and Joint Disease in Diabetes Mellitus. Endocrinol Metab Clin North Am. 1996;25(2):473-483. doi: https://doi.org/10.1016/s0889-8529(05)70335-2

3. Lundbaek K. Stiff hands $n$ long-term diabetes. Acta Med Scand. 1957;158(6):447-451

doi: https://doi.org/10.1111/j.0954-6820.1957.tb15511.x
4. Rosenbloom AL, Grgic A, Frias JL. Diabetes Mellitus, Short Stature and Joint Stiffness a New Syndrome. Pediatr Res. 1974;8(4):441-441. doi: https://doi.org/10.1203/00006450-197404000-00608

5. Rosenbloom AL, Silverstein JH, Lezotte DC, et al. Limited joint mobility in childhood diabetes mellitus indicates increased risk for microvascular disease. N Engl J Med. 1981;305(4):191-194. doi: https://doi.org/10.1056/NEJM198107233050403

6. Rosenbloom AL. Skeletal and Joint Manifestations of Childhood Diabetes. Pediatr Clin North Am. 1984;31(3):569-589. doi: https://doi.org/10.1016/s0031-3955(16)34607-7

7. Smith LL, Burnet SP, McNeil JD. Musculoskeletal manifestations of diabetes mellitus. Br J Sports Med. 2003;37(1):30-35. doi: https://doi.org/10.1136/bjsm.37.1.30 
8. Jennings AM, Milner PC, Ward JD. Hand

abnormalities are associated with the complications of diabetes in type 2 diabetes. Diabet Med. 1989;6(1):43-47. doi: https://doi.org/10.1111/j.1464-5491.1989.tb01137.x

9. Gamstedt A, Holm-Glad J, Ohlson CG, Sundstrom M. Hand abnormalities are strongly associated with the duration of diabetes mellitus. J Intern Med. 1993;234(2):189-193. doi: https://doi.org/10.1111/j.1365-2796.1993.tb00729.x

10. Sukenik S, Weitzman S, Buskila D, et al. Limited joint mobility and other rheumatological manifestations in diabetic patients. Diabete Metab. 1987;13(3):187-192.

11. Arkkila PET, Kantola IM, Viikari JSA. Limited Joint Mobility in NonInsulin-Dependent Diabetic (NIDDM) Patients: Correlation to Control of Diabetes, Atherosclerotic Vascular Disease, and Other Diabetic Complications. J Diabetes Complications. 1997;11(4):208-217. doi: https://doi.org/10.1016/s1056-8727(96)00038-4

12. Паневин Т.С., Алекперов Р.Т., Мельниченко Г.А. Синдром Рейно в практике эндокринолога // Ожирение и метаболизм. 2019. - T. 16. - №4. - C.37-45 [Panevin TS, Alekperov RT, Melnichenko GA. Raynaud's phenomenon in the endocrinologist's practice. Obesity and metabolism. 2019;16(4):37-45 (in press). (In Russ.)] doi: https://doi.org/10.14341/omet10245

13. Sauseng S, Kästenbauer T, Irsigler K. Limited joint mobility in selected hand and foot joints in patients with type 1 diabetes mellitus: a methodology comparison. Diabetes Nutr Metab. 2002;15(1):1-6.

14. Starkman HS, Gleason RE, Rand LI, et al. Limited joint mobility (LJM) of the hand in patients with diabetes mellitus: relation to chronic complications. Ann Rheum Dis. 1986;45(2):130-135. doi: https://doi.org/10.1136/ard.45.2.130

15. Abate M, Schiavone C, Pelotti P, Salini V. Limited joint mobility in diabetes and ageing: recent advances in pathogenesis and therapy. Int J Immunopathol Pharmacol. 2010;23(4):997-1003. doi: https://doi.org/10.1177/039463201002300404

16. Saito M, Marumo K. Collagen cross-links as a determinant of bone quality: a possible explanation for bone fragility in aging osteoporosis, and diabetes mellitus. Osteoporos Int. 2010;21(2):195-214. doi: https://doi.org/10.1007/s00198-009-1066-z

17. Vazzana N, Santilli F, Cuccurullo C, Davi G. Soluble forms of RAGE in internal medicine. Intern Emerg Med. 2009;4(5):389-401. doi: https://doi.org/10.1007/s11739-009-0300-1

18. Goldin A, Beckman JA, Schmidt AM, Creager MA. Advanced glycation end products: sparking the development of diabetic vascular injury. Circulation. 2006;114(6):597-605 doi: https://doi.org/10.1161/CIRCULATIONAHA.106.621854

19. Florys B, Głowin'ska B, Urban M, Peczyn'ska J. Metalloproteinases MMP-2 and MMP-9 and their inhibitors TIMP-1 and TIMP-2 levels in children and adolescents with type 1 diabetes. Endokrynol Diabetol Chor Przemiany Materii Wieku RozW. 2006;12(3):184-189.

20. Wang SH, Sun ZL, Guo YJ, et al. PPARgammamediated advanced glycation end products regulation of neural stem cells. Mol Cell Endocrinol. 2009;307(1-2):176-184. doi: https://doi.org/10.1016/j.mce.2009.02.012

21. Oliva F, Via AG, Maffulli N. Physiopathology of intratendinous calcific deposition. BMC Med. 2012;10:95. doi: https://doi.org/10.1186/1741-7015-10-95

22. Rui YF, Lui PP, Chan LS, et al. Does erroneous differentiation of tendon-derived stem cells contribute to the pathogenesis of calcifying tendinopathy? Chin Med J (Engl). 2011;124(4):606-610. doi: https://doi.org/10.3760/cma.j.issn.0366-6999.2011.04.022

23. Abate M, Schiavone C, Salini S. Neoangiogenesis is reduced in chronic tendinopathies of type 2 diabetic patients. Int J Immunopathol Pharmacol. 2012;25(3):757-761. doi: https://doi.org/10.1177/039463201202500322

24. Мокрышева Н.Г., Еремкина А.К., Мирная С.С., и др. Патологические изменения в суставах и мышцах при первичном гиперпаратиреозе // Остеопороз и остеопатии. - 2018. T. 21. — №4. - C. 10-18. [Mokrysheva NG, Eremkina AK, Mirnaya SS, et al. Joint and muscle involvement in primary hyperparathyroidism. Osteoporosis and Bone Diseases. 2018;(21)4:10-18. (In Russ.)] doi: https://doi.org/10.14341/osteo9783

25. Berry PA, Jones SW, Cicuttini FM, et al. Temporal relationship between serum adipokines, biomarkers of bone and cartilage turnover, and cartilage volume loss in a population with clinical knee osteoarthritis. Arthritis Rheum. 2011;63(3):700-707. doi: https://doi.org/10.1002/art.30182
26. Bakker K, Apelqvist J, Lipsky BA, et al. The 2015 IWGDF guidance documents on prevention and management of foot problems in diabetes: development of an evidence-based global consensus. Diabetes Metab Res Rev. 2016;32 Suppl 1:2-6. doi: https://doi.org/10.1002/dmrr.2694

27. Francia P, Seghieri G, Gulisano M, et al. The role of joint mobility in evaluating and monitoring the risk of diabetic foot ulcer. Diabetes Res Clin Pract. 2015;108(3):398-404. doi: https://doi.org/10.1016/j.diabres.2015.04.001

28. Masson EA, Hay EM, Stockley l, et al. Abnormal foot pressures alone may not cause ulceration. Diabet Med. 1989;6(5):426-428. doi: https://doi.org/10.1111/j.1464-5491.1989.tb01198.x

29. Fernando DJ, Masson EA, Veves A, Boulton AJ. Relationship of limited joint mobility to abnormal foot pressures and diabetic foot ulceration. Diabetes Care. 1991;14(1):8-11. doi: https://doi.org/10.2337/diacare.14.1.8

30. Catterall RC, Martin MM, Oakley W. Aetiology and management of lesions of the feet in diabetes. Br Med J. 1956;2(4999):953-957. doi: https://doi.org/10.1136/bmj.2.4999.953

31. Delbridge L, Ctercteko G, Fowler C, et al. The aetiology of diabetic neuropathic ulceration of the foot. Br J Surg. 1985;72(1):1-6. doi: https://doi.org/10.1002/bjs.1800720102

32. Birke JA, Cornwall MW, Jackson M. Relationship between Hallux Limitus and Ulceration of the Great Toe. J Orthop Sports Phys Ther. 1988;10(5):172-176. doi: https/doi.org/10.2519/jospt.1988.10.5.172

33. Delbridge L, Perry P, Marr S, et al. Limited joint mobility in the diabetic foot: relationship to neuropathic ulceration. Diabet Med. 1988;5(4):333-337. doi: https://doi.org/10.1111/j.1464-5491.1988.tb01000.x

34. Giacomozzi C, D'Ambrogi E, Uccioli L, Macellari V. Does the thickening of Achilles tendon and plantar fascia contribute to the alteration of diabetic foot loading? Clin Biomech (Bristol, Avon). 2005;20(5):532539. doi: https://doi.org/10.1016/j.clinbiomech.2005.01.011

35. Cheuy VA, Hastings MK, Commean PK, Mueller MJ. Muscle and Joint Factors Associated With Forefoot Deformity in the Diabetic Neuropathic Foot. Foot Ankle Int. 2016;37(5):514-521. doi: https://doi.org/10.1177/1071100715621544

36. Mueller MJ, Minor SD, Sahrmann SA, et al. Differences in the gait characteristics of patients with diabetes and peripheral neuropathy compared with age-matched controls. Phys Ther. 1994;74(4):299-308; discussion 309-213. doi: https://doi.org/10.1093/ptj/74.4.299

37. Searle A, Spink MJ, Ho A, Chuter VH. Association between ankle equinus and plantar pressures in people with diabetes. A systematic review and meta-analysis. Clin Biomech (Bristol, Avon). 2017;43:8-14. doi: https://doi.org/10.1016/j.clinbiomech.2017.01.021

38. Lavery LA, Armstrong DG, Boulton AJ, Diabetex Research G. Ankle equinus deformity and its relationship to high plantar pressure in a large population with diabetes mellitus. J Am Podiatr Med Assoc 2002;92(9):479-482. doi: https://doi.org/10.7547/87507315-92-9-479

39. Holewski JJ, Moss KM, Stess RM, et al. Prevalence of foot pathology and lower extremity complications in a diabetic outpatient clinic. J Rehabil Res Dev. 1989;26(3):35-44

40. van $\mathrm{Schie} \mathrm{CH}$, Vermigli $\mathrm{C}$, Carrington AL, Boulton A. Muscle weakness and foot deformities in diabetes: relationship to neuropathy and foot ulceration in caucasian diabetic men. Diabetes Care. 2004;27(7):1668-1673. doi: https://doi.org/10.2337/diacare.27.7.1668

41. Hilton TN, Tuttle LJ, Bohnert KL, et al. Excessive adipose tissue infiltration in skeletal muscle in individuals with obesity, diabetes mellitus, and peripheral neuropathy: association with performance and function. Phys Ther. 2008;88(11):1336-1344. doi: https://doi.org/10.2522/ptj.20080079

42. Zimny $\mathrm{S}$, Schatz $\mathrm{H}$, Pfohl M. The role of limited joint mobility in diabetic patients with an at-risk foot. Diabetes Care. 2004;27(4):942-946 doi: https://doi.org/10.2337/diacare.27.4.942

43. Hicks J. The mechanics of the foot, II. The plantar aponeurosis and the arch. J Anat. 1954:88(1):25-30.

44. Walters DP, Gatling W, Mullee MA, Hill RD. The distribution and severity of diabetic foot disease: a community study with comparison to a non-diabetic group. Diabet Med. 1992;9(4):354-358. doi: https://doi.org/10.1111/j.1464-5491.1992.tb01796.x

45. Melling M, Reihsner R, Pfeiler W, et al. Comparison of palmar aponeuroses from individuals with diabetes Mellitus and Dupuytren's contracture. Anat Rec. 1999;255(4):401-406. doi: https://doi.org/10.1002/(sici)10970185(19990801)255:4<401::aid-ar6>3.0.co;2-d 
46. Duffin AC, Lam A, Kidd R, et al. Ultrasonography of plantar soft tissues thickness in young people with diabetes. Diabet Med. 2002;19(12):1009-1013. doi: https://doi.org/10.1046/j.1464-5491.2002.00850.x

47. Francia P, Anichini R, Seghieri G, et al. History, Prevalence and Assessment of Limited Joint Mobility, from Stiff Hand Syndrome to Diabetic Foot Ulcer Prevention: A Narrative Review of the Literature. Curr Diabetes Rev. 2018;14(5):411-426. doi: https://doi.org/10.2174/1573399813666170816142731

48. Ramchurn N, Mashamba C, Leitch E, et al. Upper limb musculoskeletal abnormalities and poor metabolic control in diabetes. Eur J Intern Med. 2009;20(7):718-721. doi: https://doi.org/10.1016/j.ejim.2009.08.001

49. Francia P, Gulisano M, Anichini R, Seghieri G. Diabetic foot and exercise therapy: step by step the role of rigid posture and biomechanics treatment. Curr Diabetes Rev. 2014;10(2):86-99. doi: https://doi.org/10.2174/1573399810666140507112536

50. Joslin EP. The Menace of Diabetic Gangrene. N Engl J Med. 1934;211(1):16-20.doi:https://doi.org/10.1056/nejm193407052110103

51. Birke JA, Cornwall MW, Jackson M. Relationship between Hallux Limitus and Ulceration of the Great Toe. J Orthop Sports Phys Ther. 1988;10(5):172-176. doi: https://doi.org/10.2519/jospt.1988.10.5.172

52. Brand PW. Mechanical Factors in Joint Stiffness and Tissue Growth. J Hand Ther. 1995;8(2):91-96. doi: https://doi.org/10.1016/s0894-1130(12)80305-x

53. Francia P, Anichini R, Seghieri G, et al. History, Prevalence and Assessment of Limited Joint Mobility, from Stiff Hand Syndrome to Diabetic Foot Ulcer Prevention: A Narrative Review of the Literature. Curr Diabetes Rev. 2018;14(5):411-426. doi: https://doi.org/10.2174/1573399813666170816142731
54. Dijs HM, Roofthooft JM, Driessens MF, et al. Effect of physical therapy on limited joint mobility in the diabetic foot. A pilot study. J Am Podiatr Med Assoc. 2000;90(3):126-132. doi: https://doi.org/10.7547/87507315-90-3-126

55. Lawall H, Diehm C. Diabetic foot syndrome from the perspective of angiology and diabetology. Orthopade. 2009;38(12):1149-1159. doi: https://doi.org/10.1007/s00132-009-1501-z

56. Горохов С.В., Удовиченко О.В., Галстян Г.Р., и др. Внутриобувная компьютерная педобарография как новый метод оценки эффективности ортопедической обуви у больных сахарным диабетом. // Сахарный диабет. - 2009. - T. 12. - №4. C. 81-85. [Gorokhov SV, Udovichenko OV, Galstyan GR, et al. In-shoe computed pedobarography as a new method for the assessment of efficiency of orthopedic footwear in diabetic patients. Diabetes mellitus. 2009;12(4):81-85. (In Russ.)] doi: http://doi.org/10.14341/2072-0351-5710

57. Kim JB, Song BW, Park S, et al. Alagebrium chloride, a nove advanced glycation end-product cross linkage breaker, inhibits neointimal proliferation in a diabetic rat carotid balloon injury model. Korean Circ J. 2010;40(10):520-526. doi: https://doi.org/10.4070/kcj.2010.40.10.520

58. Engelen L, Stehouwer CD, Schalkwijk CG. Current therapeutic interventions in the glycation pathway: evidence from clinical studies. Diabetes Obes Metab. 2013;15(8):677-689. doi: https://doi.org/10.1111/dom.12058

59. Hudson BI, Bucciarelli LG, Wendt T, et al. Blockade of receptor for advanced glycation endproducts: a new target for therapeutic intervention in diabetic complications and inflammatory disorders. Arch Biochem Biophys. 2003;419(1):80-88. doi: https://doi.org/10.1016/j.abb.2003.08.030

\section{ИНФОРМАЦИЯ ОБ АВТОРАХ [AUTHORS INFO]}

*Паневин Тарас Сергеевич [Taras S. Panevin, MD]; адрес: Россия, 117036, Москва, ул. Дм. Ульянова, д. 11 [address: 11 Dm. Ulyanova street, 117036 Moscow, Russia]; ORCID: http://orcid.org/0000-0002-5290-156X; eLibrary SPIN-код: 7839-3145; e-mail: tarasel@list.ru

Алексеева Людмила Ивановна, д.м.н., професcop [Lyudmila I. Alekseeva, MD, PhD, Professor]; адрес: Россия, 115522, Москва, Каширское шоссе, д. 34A [address: 34A Kashirskoe Shosse, 115522 Moscow, Russia]; ORCID: https://orcid.org/0000-0001-7017-0898; eLibrary SPIN: 4714-8572; e-mail: dr.alekseeva@gmail.com

Таскина Елена Александровна, к.м.н. [Elena A. Taskina, MD, PhD]; адрес: Россия, 115522, Москва, Каширское шоссе, д. 34A [address: 34A Kashirskoe Shosse, 115522 Moscow, Russia]; ORCID: https://orcid.org/0000-0001-8218-3223; eLibrary SPIN: 8866-7146; e-mail: braell@mail.ru Кашеварова Наталья Гаврииловна, к.м.н. [Natalia G. Kashevarova, MD, PhD]; адрес: Россия, 115522, Москва, Каширское шоссе, д. 34A [address: 34A Kashirskoe Shosse, 115522 Moscow, Russia]; ORCID: https://orcid.org/0000-0001-8732-2720; eLibrary SPIN: 4289-9475; e-mail: nat-kash@yandex.ru

\section{ЦИТИРОВАТЬ:}

Паневин Т.С., Алексеева Л.И., Таскина Е.А., Кашеварова Н.Г. Синдром ограниченной подвижности суставов как предиктор развития синдрома диабетической стопы // Остеопороз и остеопатии. — 2019. — Т. 22. — №3. — С.19-26. doi: https://doi.org/10.14341/osteo12280

\section{TO CITE THIS ARTICLE:}

Panevin TS, Alekseeva LI, Taskina EA, Kashevarova NG. Limited joint mobility syndrome as a predictor of the diabetic foot syndrome. Osteoporosis and bone diseases. 2019;22(3):19-26. doi: https://doi.org/10.14341/osteo12280 